\title{
RESPON SISWA TERHADAP PENGEMBANGAN MEDIA PEMBELAJARAN INTERAKTIF BERBASIS ANDROID
}

\author{
Ketut Sepdyana Kartini ${ }^{1}$, I Nyoman Tri Anindia Putra ${ }^{2}$ \\ ${ }^{12}$ Teknik Informatika, STMIK STIKOM Indonesia, Indonesia
}

\author{
A R T I C L E I N F O \\ Article history: \\ Received 23 Februari 2020 \\ Received in revised form \\ 26 Februari 2020 \\ Accepted 28 Maret 2020 \\ Available online 30 April \\ 2020
}

\section{Kata Kunci:}

Respon, media

pembelajaran, android, tata

nama senyawa

\begin{abstract}
A B S T R A K
Penelitian sebelumnya telah dikembangkan media pembelajaran interaktif berbasis android pada materi Tata Nama IUPAC Senyawa Anorganik, namun belum diketahui respon siswa SMAN 4 Denpasar terhadap media pembelajaran tersebut. Penelitian ini bertujuan untuk mengetahui respon siswa terhadap media pembelajaran interaktif berbasis android di SMAN 4 Denpasar. Penelitian menggunakan metode deskriptif. Teknik pengumpulan data menggunakan teknik angket. Instrument yang digunakan adalah Beta Test berupa lembar angket respon siswa dengan pertanyaan tertutup dan menggunakan skala Linkert. Hasil penelitian di peroleh berdasarkan hasil angket respon siswa terhadap media pembelajaran berbasis android pada materi tata nama IUPAC senyawa anorganik mendapatkan presentase rata-rata sebesar pada beta test I 76,41 \% dengan kategori baik dan hasil angket respon siswa pada beta test II mendapatkan presentase rata-rata sebesar 83,07 \% dengan kategori sangat baik.
\end{abstract}

\begin{abstract}
Previous research has been developed on Android-based interactive learning media on IUPAC Inorganic Compound material, but the response of SMAN 4 Denpasar students to the learning media is unknown. This research aims to determine student's responses to android-based interactive learning media at SMAN 4 Denpasar. Research using descriptive methods. Data collection techniques using a questionnaire technique. The instrument used was a Beta Test in the form of a student questionnaire response sheet with closed questions and using the Linkert scale. The results of the study were obtained based on the results of student questionnaire responses to the Android-based learning media on the IUPAC nomenclature of inorganic compounds get an average percentage of $76.41 \%$ in the beta test I with good categories and the results of the questionnaire responses of students in the beta test II get an average percentage average of $83.07 \%$ with a very good category.
\end{abstract}

Keywords: Response, Learning media, Android, Nomenclature Compounds.

\section{Pendahuluan}

Perkembangan ilmu pengetahuan dan teknologi mengalami kemajuan yang sangat pesat dari waktu ke waktu. Dalam dunia pendidikan, seorang pendidik di tuntut untuk melakukan upaya-upaya pembaharuan terkait pemanfaatan teknologi dalam kegiatan belajar mengajar. Salah satu upaya pemanfaatan teknologi dalam proses belajar adalah pengembangan media pembelajaran. Penggunaan media pembelajaran dalam proses pengajaran sangat dianjurkan untuk mempertinggi kualitas pengajaran (Sudjana dan Rivai, 2013).

Media dalam proses pembelajaran dapat berupa software dan hardware yang merupakan bagian kecil dari teknologi pembelajaran yang harus diciptakan atau dikembangkan, digunakan dan dikelola untuk kebutuhan pembelajaran dalam mencapai efektivitas dan efesiensi proses pembelajaran (Arsyad, 2014). Menurut Sakat (2012), pembelajaran yang menggunakan media teknologi memberikan pengaruh yang signifikan terhadap pembelajaran. Salah satu pemanfaatan teknologi sebagai media pembelajaran adalah menggunakan perangkat android. Selain digunakan sebagai alat komunikasi, perangkat android juga berpotensi dikembangkan sebagai media pembelajaran interaktif yang bermanfaat bagi peserta didik.

\footnotetext{
1 Corresponding author.

E-mail: sepdyana27@gmail.com (Ketut Sepdyana Kartini)
} 
Teknologi yang terintegrasi pada pembelajaran merupakan salah satu strategi pencapaian tujuan pembelajaran, karena teknologi bukan lagi dianggap sebagai sesuatu yang baru. Informasi ini sesuai kenyataan bahwa penggunaan perangkat mobile (smartphone, PDA atau tablet) sudah tidak asing lagi di kalangan peserta didik. Kebanyakan peserta didik SMA memiliki handphone yang memiliki fitur yang lebih up to date. Smartphone yang menjadi tren masa kini yang berkembang sangat pesat adalah android, sehingga pengembangan media pembelajaran menggunakan android ini cukup menjanjikan (Lubis dan Ikhsan 2015)

Pengembangan media pembelajaran menggunakan kecanggihan teknologi sangatlah pesat. Hampir semua mata pelajaran mengimplementasikan media pembelajarana dalam kegiatan belajar mengajar. Pelajaran kimia merupakan salah satu mata pelajaran di bidang sains, yang mana bagi peserta didik kelas $\mathrm{X}$ merupakan mata pelajaran yang masih baru bagi siswa. Salah satu materi yang dianggap sulit oleh siswa kelas X adalah materi tata nama International Union of Pure and Applied Chemistry (IUPAC) senyawa anorganik. Belajar kimia memiliki konsep dasar tata nama senyawa yang harus dapat dimengerti oleh siswa SMA. Hal ini dikarenakan antara satu materi dengan materi lainnya saling berkesinambungan. (Sasmito et al., 2000 dalam Kartini et al., 2019).

Pada penelitian terdahulu yang dilakukan oleh Kartini et al (2019), telah dikembangkan media pembelajaran berbasis android untuk siswa kelas X pada materi tata nama IUPAC senyawa anorganik. Media pembelajaran yang dikembangkan berupa aplikasi pada perangkat smartphone dengan sistem operasi android. Media tersebut di validasi menggunakan instrument alpha test menunjukkan bahwa media pembelajaran sangat baik dan dapat di gunakan. Namun belum di ukur respon siswa terkait media pembelajaran tersebut.

Pembelajaran yang menarik membuat siswa lebih senang dan mudah menyerap ilmu yang terlihat dari respon siswa selama proses pembelajaran. Respon siswa merupakan reaksi sosial yang dilakukan siswa dalam menanggapi pengaruh atau rangsangan dari situasi yang dilakukan orang lain (Maharani \& Widhiasih, 2016). Sebagai seorang pendidik sangatlah penting untuk mengetahui respon siswa dalam kegiatan belajar mengajar. Pendidik diharapkan memahami cara berpikir siswa dan mampu mengarahkan siswa untuk mengubah cara berpikir yang baik dan benar. Sehingga pendidik akan mengetahui letak kesalahan yang dilakukan siswa. Kesalahan tersebut dapat dijadikan sumber informasi belajar siswa agar tidak terulang kembali. Sehingga siswa akan memiliki pemahaman yang lebih baik.

Berdasarkan latar belakang diatas, peneliti tertarik untuk melakukan penelitian tentang analisis respon siswa terhadap media pembelajaran berbasis android pada materi tata nama IUPAC senyawa anorganik. Penelitian ini bertujuan untuk mengetahui respon siswa terhadap media pembelajaran android pada materi tata nama IUPAC senyawa anorganik.

\section{Metode}

Penelitian ini adalah penelitian deskriptif dengan pendekatan kualitatif. Penelitian ini bersifat deskriptif karena bertujuan untuk membuat deskripsi, gambaran secara sistematis atau terperinci tentang respon siswa terhadap media pembelajaran berbasis android pada materi tata nama IUPAC senyawa anorganik di SMAN 4 Denpasar. Data yang dikumpulkan dalam penelitian ini menggunakan teknik angket. Teknik angket merupakan suatu teknik atau cara pengumpulan data secara tidak langsung (peneliti tidak langsung bertanya-tanya dengan responden) (Sugiyono, 2015). Peneliti menggunakan angket berupa pertanyaan yang digunakan untuk mengidentifikasi karakteristik siswa dan berupa pertanyaan yang digunakan untuk mengetahui respon siswa terhadap penggunaan media mpembelajaran yang dikembangkan. Instrument penelitian yang digunakan untuk mendapatkan informasi dan pengumpulan data. Instrumen yang digunakan dalam penelitian ini adalah instrument beta test.

Analisis data angket penilaian siswa terhadap media pembelajaran yang dikembangkan menggunakan cara skala Likert (Sugiyono, 2015). 
Tabel 1. Pedoman Skor Penilaian oleh Mahasiswa

\begin{tabular}{ccc}
\hline Penilaian & Keterangan & Skor \\
\hline SS & Sangat Setuju & 5 \\
S & Setuju & 4 \\
KS & Kurang Setuju & 3 \\
TS & Tidak Setuju & 2 \\
STS & Sangat Tidak Setuju & 1 \\
\hline
\end{tabular}

Selanjutnya seluruh data dari angket penilaian siswa direkapitulasi dan dilakukan perhitungan tiap butir pernyataan menggunakan rumus berikut.

$$
\mathrm{P}=\frac{\text { jumlah skor hasil pengumpulan data }}{\text { jumlah skor kriterium }} \times 100 \%
$$

Ket: $\mathrm{P}=$ persentase per item pernyataan

Berdasarkan perhitungan yang telah dilakukan, maka dilakukan interpretasi skor angka menjadi suatu kategori. Kategori tersebut adalah sangat baik, baik, cukup, kurang, dan sangat kurang seperti diberikan pada Tabel 2 .

Tabel 2. Kriteria Interpretasi Skor

\begin{tabular}{ccc}
\hline No & Interval Skor $(\%)$ & Kategori \\
\hline 1 & $81-100$ & Sangat Baik \\
2 & $61-80$ & Baik \\
3 & $41-60$ & Cukup \\
4 & $21-40$ & Kurang \\
5 & $0-20$ & Sangat Kurang \\
\hline
\end{tabular}

Analisis ini bertujuan untuk menentukan dan menyimpulkan respon siswa terhadap media pembelajaran berbasis android pada materi tata nama IUPAC senyawa anorganik.

\section{Hasil dan pembahasan}

Beta test dilakukan dengan mengujicobakan aplikasi pembelajaran kepada responden. Responden yang dimaksud pada tahap ini adalah siswa kelas X sebanyak 34 responden. Sebelum melaksanakan pengujian, peneliti menjelaskan secara singkat prosedur pengujian dan cara penggunaan aplikasi. Kemudian masing-masing responden menggunakan media pembelajaran berbasis android materi tata nama IUPAC senyawa anorganik di perangkat smartphone masing-masing. Setelah itu responden diminta mengisi angket untuk memberikan penilaian, saran dan komentar terhadap media pembelajaran yang diujicobakan. Berikut data yang diperoleh dari beta test dapat dilihat pada Tabel 3. 
Tabel 3. Hasil Angket Respon Siswa Pada Beta Test

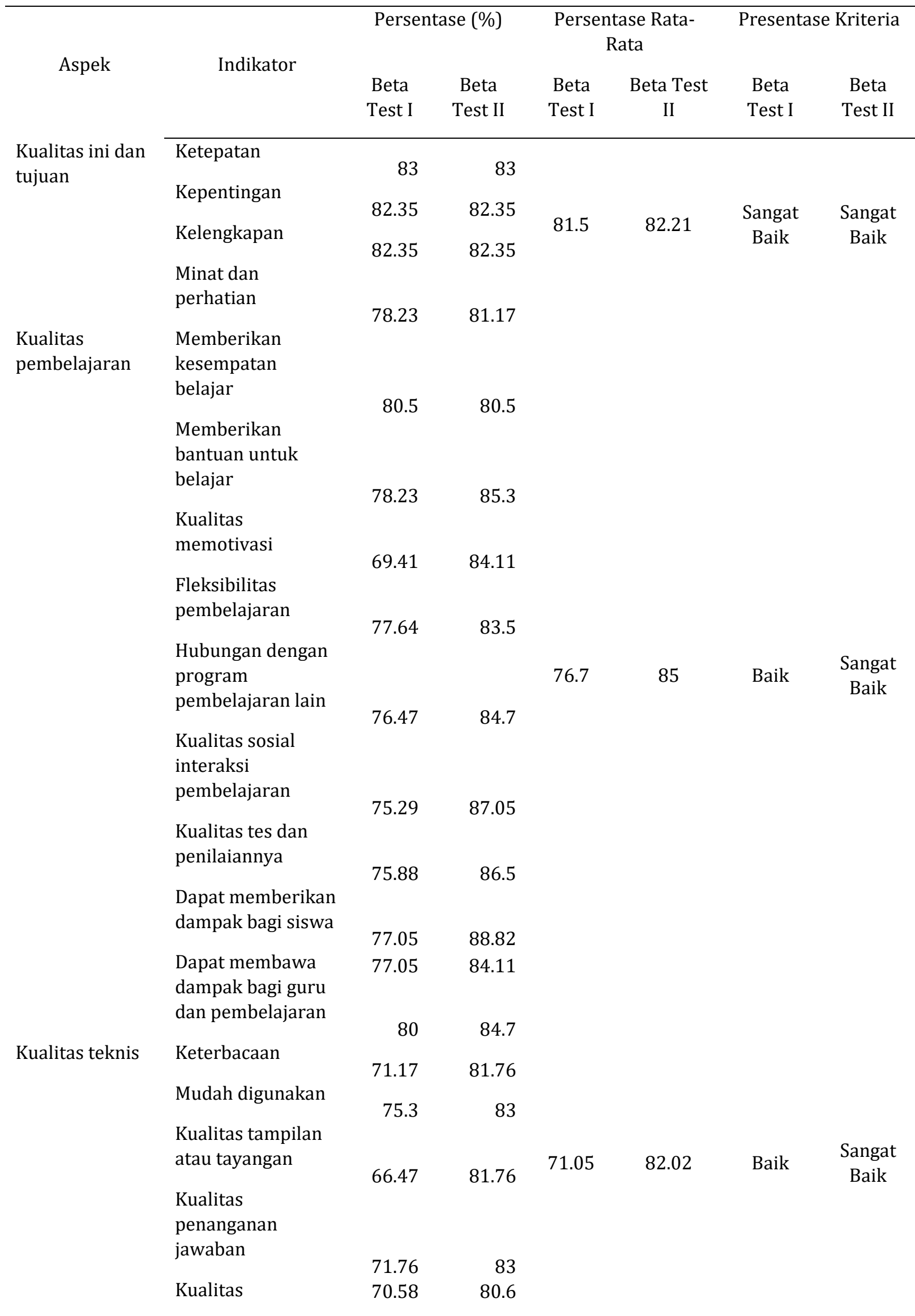


pendokumenatsian

nya

$$
\begin{array}{llll}
\text { Rata-rata hasil pengembangnnya } & 76,41 \% & 83,07 \% & \text { Baik }
\end{array} \begin{gathered}
\text { Sangat } \\
\text { Baik }
\end{gathered}
$$

Berdasarkan Tabel 3. terdapat peningkatan nilai persentase dari hasil pengujian sebelumnya pada setiap indikator. Aspek-aspek yang dinilai pada beta test II memperoleh kriteria rata-rata sangat baik dengan presentase sebesar 83,07 \%. Aspek komponen yang mendapatkan presentase rata-rata terbesar adalah pada aspek kualitas pembelajaran. Kemudian pada aspek kualitas isi dan tujuan pada media pembelajaran mendapatkan presentase rata-rata sebesar $82,21 \%$, sedangkan pasa aspek kualitas teknis mendapatkan presentase rata-rata sebesar 82,02 $\%$.

Tahap akhir setelah melakukan beta test I, terdapat beberapa aspek yang dapat dikembangkan sehingga dilakukan revisi akhir. Revisi dilakukan berdasarkan saran-saran yang diberikan oleh responden. Berikut saran-saran yang diberikan responden dan perbaikan yang dapat dilakukan

Tabel 4. Revisi Media Setelah Beta Test

\begin{tabular}{lll}
\hline No & \multicolumn{1}{c}{ Sebelum revisi } & \multicolumn{1}{c}{ Setelah Revisi } \\
\hline 1. & Tampilan menu kurang menarik & $\begin{array}{l}\text { Tampilan menu di perbaiki dengan } \\
\text { menambahkan gambar yang sesuai } \\
\text { dengan judul menu }\end{array}$ \\
2. & Latar latihan dan kuis sama & $\begin{array}{l}\text { Memperbaiki tampilan latar pada kuis } \\
\text { dan lebih menarik }\end{array}$ \\
3. & Soal -soal kuis sedikit & Soal kuis di perbanyak \\
\hline
\end{tabular}

1. Tampilan menu kurang menarik

Setelah dilakukan beta test I, saran dan komentar yang diberikan adaah perbaharui tampilan agar lebih menarik, sehingga dilakukan revisi pada tampilan menu awal yang digunakan pada halaman ini.

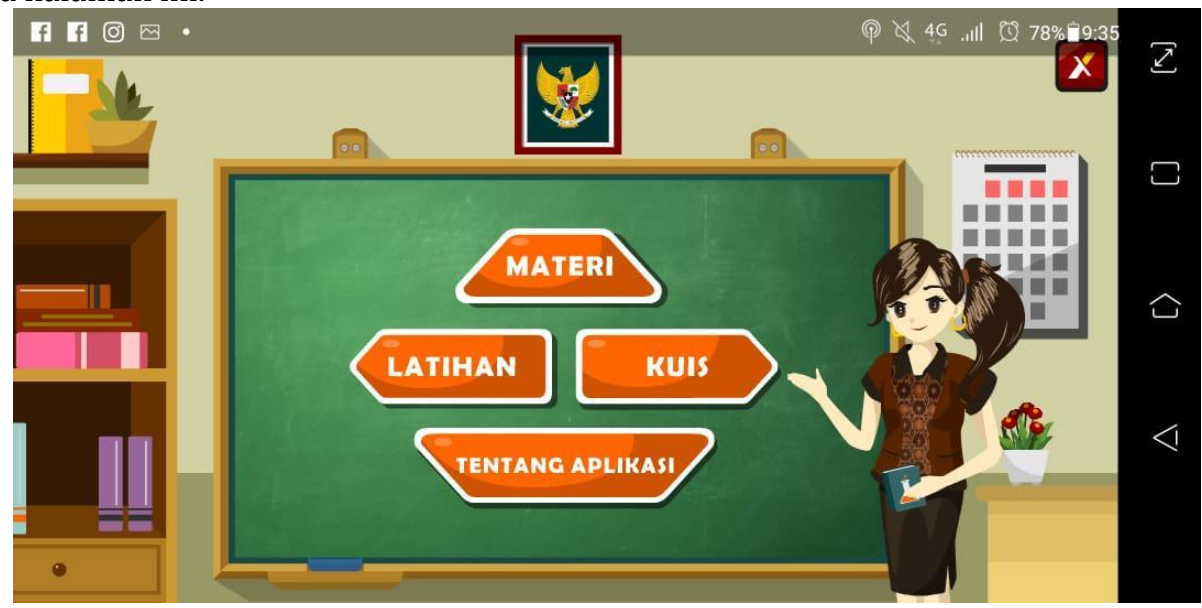

(a) Sebelum revisi 


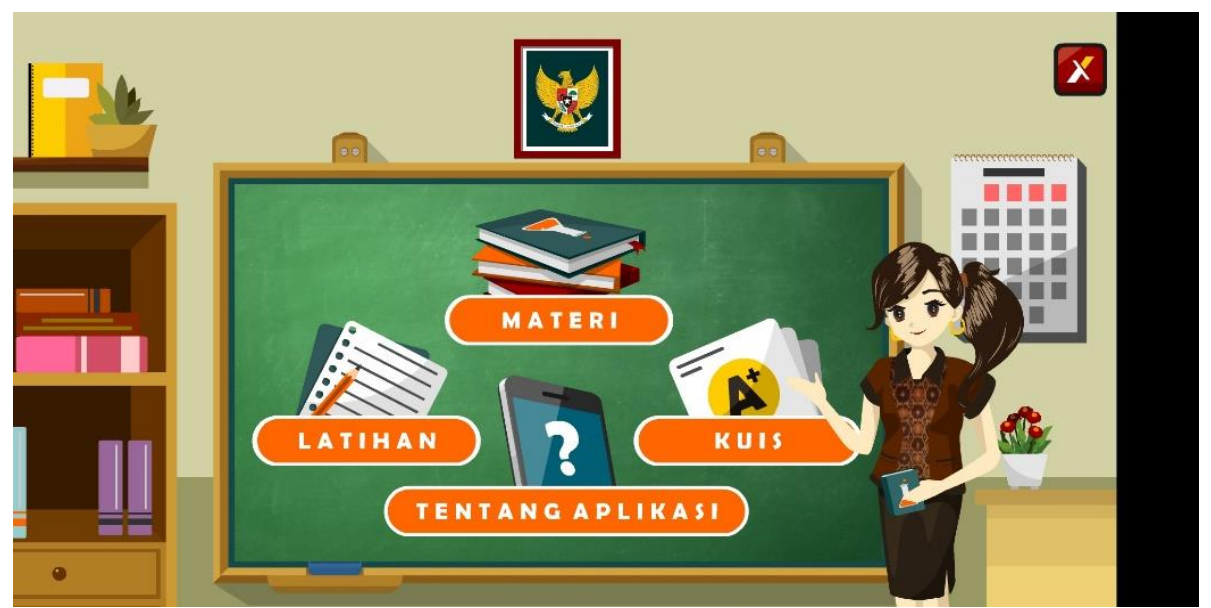

(b) Sesudah revisi

\section{Gambar 1. Perubahan Pada Halaman Menu Utama}

Adanya revisi ini diharapkan dapat menarik minat siswa ketika membuka aplikasi dikarenakan halaman ini adalah halaman pertama yang terlihat ketika menjalankan aplikasi.

2. Latar latihan dan kuis sama

Selain halaman tampilan awal, haaman kuis dan latihan soal juga diminta untuk diperbaharui.

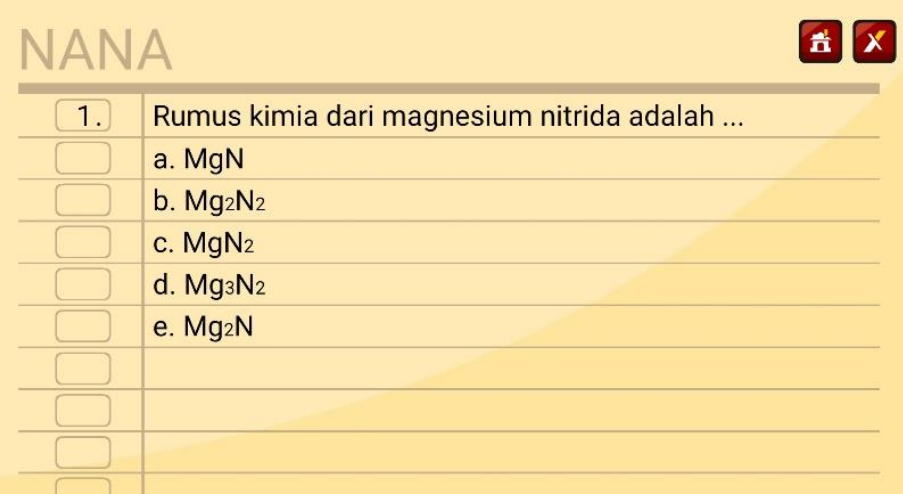

(a) Tampilan halaman Kuis sebelum di revisi

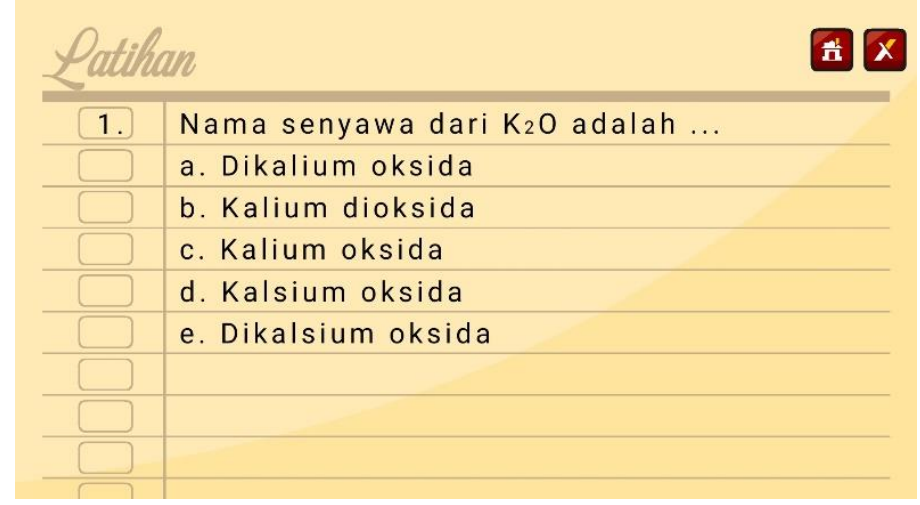

(b) Tampilan halaman latihan sebelum di revisi 


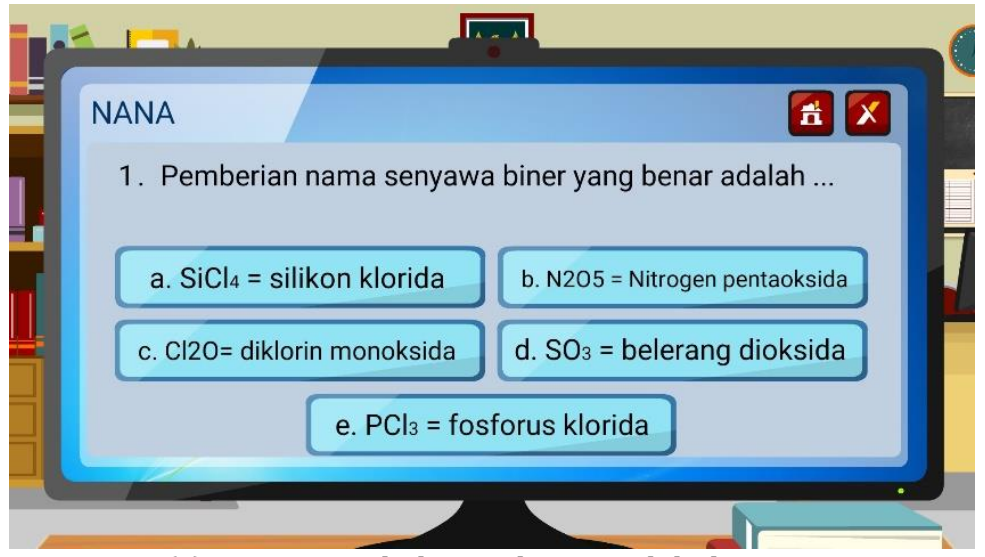

(c) Tampian halaman kuis setelah di revisi

Revisi yang dilakukan pada tampilan ini dilakukan sesuai saran dari pengguna agar media dapat menarik minat siswa untuk memahami pembelajaran yang disampaiaka pada isi media.

3. Soal-soal kuis sedikit

Sebelum dilakukan revisi, soal pada kuis berjumlah 10 soal. Kemudian ditambahkan 10 soal lagi, sehingga total soal pada halaman kuis berjumlah 20 soal.

\section{Simpulan dan saran}

Berdasarkan pemaparan hasil dan pembahasan di atas, maka dapat ditarik kesimpulan yaitu hasil angket respon siswa terhadap media pembelajaran berbasis android pada materi tata nama IUPAC senyawa anorganik mendapatkan presentase rata-rata sebesar pada beta test I 76,41\% dengan kategori baik dan hasil angket respon siswa pada beta test II mendapatkan presentase rata-rata sebesar 83,07 \% dengan kategori sangat baik.

Adapun saran untuk penelitian selanjutnya yaitu, media pembelajaran berbasis android untuk siswa pada materi tata nama IUPAC senyawa anorganik yang dihasilkan perlu dilakukan penelitian lebih lanjut untuk mengetahui keefektifan atau hasil belajar siswa terhadap penggunaan media ini.

\section{Daftar Rujukan}

Anggraeni, R dan Kustijono, R. 2013. Pengembangan media animasi fisika pada materi cahaya dengan aplikasi flash berbasis android. Jurnal Pendidikan Fisika dan Aplikasinya (JPFA), 3 (1), 1118.

Ardiansyah, A. A. I., Irwandi, D., \& Murniati, D. 2016. Analisis Literasi Sains Siswa Kelas XI IPA Pada Materi Hukum Dasar Kimia di Jakarta Selatan. EduChemia (Jurnal Kimia dan Pendidikan), 1(2), 149-161.

Arsyad, A. 2014. Media pembelajaran. Jakarta: Rajawali Pers.

Astra, I.M., Umiatin, dan Ruharman, D. 2012. Aplikasi Mobile Learning Fisika dengan Menggunakan Adobe Flash sebagai Media Pembelajaran Pendukung. Jurnal Pendidikan dan Kebudayaan, 18 (2): 174-180.

Ismawati, R., Saptorini, dan Wijayati, N. 2013. Pengaruh Model Pembelajaran Inkuiri Berstrategi React Terhadap Hasil Belajar Kimia Siswa SMA Kelas XI. Jurnal Inovasi Pendidikan Kimia. Vol 7, No 1, Hal. 1044-1050.

Kartini, Ketut Sepdyana, dan I Ketut Setiawan. 2019. Pengembangan Media Pembelajaran Interaktif Tata Nama Iupac Senyawa Anorganik Berbasis Android. Jurnal Pendidikan dan Pembelajaran 3: 238-45.

Kirna, I Made. 2012. Pemahaman Konseptual Pembelajaran Kimia Pemula dalam Pembelajaran Berbantuan Multimedia Interaktif. Jurnal Ilmu Pendidikan, Jilid 18, nomor 1, juni 2012, hlm. 88-97 
Lubis, Isma Ramadhani, and Jaslin Ikhsan. 2015. "Pengembangan Media Pembelajaran Kimia Berbasis Android Untuk Meningkatkan Motivasi Belajar Dan Prestasi Kognitif Peserta Didik Sma." Jurnal Inovasi Pendidikan IPA 1(2): 191.

Maharani, A.A.P., dan Widhiasih, L.K.S. 2016. Respon Siswa Terhadap Umpan Balik Guru saat Pelajaran Bahasa Inggris di SD Saraswati 5 Denpasar. Jurnal Bakti Saraswati. 5(2):88-92

Mulyani, H. R. A. 2013. Pengaruh Penerapan Pembelajaran Kontekstual Terhadap Peningkatan Penguasaan Konsep Bahan Kimia Dalam Kehidupan Sehari-hari dan Keterampilan Berpikir Kritis Siswa Kelas VIII SMP Negeri 4 Metro. Jurnal Bioedukasi, Vol. 4 No. 2. Hal 114-121

Mulyanta. 2009. Tutorial membangun media interaktif media pembelajaran. Yogyakarta: Universitas Atma jaya.

Nazalin, N., dan Muhtadi, A. 2016. Pengembangan multimedia interaktif pembelajaran kimia pada materi hidrokarbon untuk siswa kelas XI SMA. Jurnal Inovasi Teknologi Pendidikan. 3(2), 221.

Puspita, D.E.K, dan Muhtadi, A. 2018. Pengembangan Multimedia Pembelajaran Interaktif Kimia Berbasis Android Menggunakan Prinsip Mayer pada Materi Laju Reaksi. Jurnal Inovasi Teknologi Pendidikan. $5(1), 38-47$.

Purwanto, D. dan Yuliani. 2013. Pengembangan Media Komik IPA Terpadu Tema Pencemaran Air Sebagai Media Pembelajaran untuk Siswa SMP Kelas VII. Jurnal Pendidikan Sains ePensa. 1 (1): 71-76.

Sakat, A. A., Mohd Zin, M. Z., Muhamad, R., Ahmad, A., Ahmad, N. A., \& Kamo, M. A. 2012. Educational technology media method in teaching and learning progress. American Journal of Applied Sciences, 874-888.

Sudria, dkk, 2011. Pengaruh Pembelajaran Interaktif Laju Reaksi Berbantuan Komputer terhadap Hasil Belajar Siswa. Jurnal Pendidikan dan Pengajaran, vol 44 no 1-3 hal 25

Sudjana, N. dan Rivai, A. 2013. Media Pengajaran. Sinar Baru Algensindo. Bandung.

Supriono, N, dan Rozi, F.2018. Pengembangan Media Pembelajaran Bentuk Molekul Kimia Menggunakan Augmented Reality Berbasis Android. Jurnal Ilmiah Penelitian dan Pembelajaran Informatika. 3(1), 53-61.

Sugiyono. 2015. Metode Penelitian Pendidikan (Pendekatan Kuantitatif, Kualitatif, dan R\&D). Alfabeta. Bandung.

Yektyastuti, R dan ikhsan, J. 2016. Pengembangan Media Pembelajaran Berbasis Android pada Materi Kelarutan untuk meningkatkan Performa Akademik Peserta didik SMA. Jurnal Inovasi Pendidikan. 2(1), 88-99.

Yektyastuti, R. 2012. Pengembangan media pembelajaran Kimia berbasis Android pada materi kelarutan dan hasil kali kelarutan untuk meningkatkan motivasi belajar dan hasil belajar kognitif peserta didik SMA. Jurnal Pembelajaran Kimia. 3(2), 8- 15. 